\title{
Investigation on cell proliferation with a new antibody against thymidine kinase 1
}

\author{
Naining Wang ${ }^{\mathrm{a}}$, Qimin $\mathrm{He}^{\mathrm{b}}$, Sven Skog ${ }^{\mathrm{b}}$, \\ Staffan Eriksson ${ }^{\mathrm{c}}$ and Bernhard Tribukait ${ }^{\mathrm{a}, *}$ \\ ${ }^{a}$ Department of Oncology and Pathology, Karolinska \\ Institute, Stockholm, Sweden \\ ${ }^{\mathrm{b}}$ Department of Oncology, KFC, Huddinge University \\ Hospital, Sweden \\ ${ }^{\mathrm{c}}$ Department of Veterinary Medical Chemistry, \\ Swedish University of Agricultural Science, \\ Biomedical Center, Uppsala, Sweden
}

Received 15 February 2001

Accepted 10 May 2001

\begin{abstract}
The cytosolic thymidine kinase 1 (TK1) is one of the enzymes involved in DNA replication. Based on biochemical studies, TK1 is activated at late G1 of cell cycle, and its activity correlates with the cell proliferation. We have developed a polyclonal anti-TK1 antibody against a synthetic peptide from the C-terminus of human TK1. Using this antibody, here we demonstrate the exclusive location of TK1 in the cytoplasm of cells. Cell cycle dependent TK1 expression was studied by simultaneous fluorescence staining for TK1 and bromodeoxyuridine, by using elutriated cells, and by quantitation of the amount TK1 in relation to the cellular DNA content. TK1, which was strongly expressed in the cells in $\mathrm{S}+\mathrm{G} 2$ period, raised at late G1 and decreased during mitosis. The amount of TK1 increased three folds from late G1 to G2. TK1 positive cells were demonstrated in areas of proliferation activity of various normal and malignant tissues. The new anti-TK1 antibody works in archival specimens and is a specific marker of cell proliferation.
\end{abstract}

Keywords: Thymidine kinase 1, polyclonal antibody, cell proliferation, cell cycle, immunochemistry

\section{Introduction}

Cell proliferation of tumors is of decisive importance for the patient's survival, metastatic spread and

\footnotetext{
*Corresponding author: Dr. Bernhard Tribukait, Department of Oncology and Pathology, Karolinska Institute, CCK R8:00, 17176 , Stockholm, Sweden. Tel.: +46 85177 4361; Fax: +46 8517 75042; E-mail: bernhard.tribukait@lab.ks.se.
}

response to therapy $[11,20,23,24,26,28,29]$. In clinical investigations, mitotic count, ${ }^{3} \mathrm{H}$-thymidine labeling index, bromodeoxyuridine (BrdU) incorporation, expression of Ki-67, proliferating cell nuclear antigen, and cyclins, as well as measurement of S-phase by means of DNA flow cytometry have been used in the assessment of cell proliferation [5,8,17,22,33,36,37]. Recently, also cell cycle related gene expression such as the expression of the p53 tumor suppressor gene has been the subject of studies relating to the prognosis of malignancies $[4,16,30]$. Further understanding of cell proliferation could help not only to discover the mechanisms involved in tumor development, but may also lead to improvements in their diagnosis and treatment.

Thymidine kinases (ATP:thymidine- $5^{\prime}$ phosphotransferase, EC 2.7.1.21) are enzymes that catalyses the thymidine to deoxythymidine monophosphate transformation, and, therefore, have a key role in the DNA metabolism. This phosphorylation is the only pathway to introduce thymidine into the DNA metabolism. From biochemical studies TK1 is known to be present in the cytosol of the cell extract.

The activity of TK1 increases at the border of G1/Sphase and reaches its highest level in late S-phase. There is a good correlation between TK activity and the amount of TK1 protein during the cell cycle [19, $25,32]$. Clinical studies of serum TK activity in a variety of tumors have demonstrated that an increase of serum TK level is related to the clinical stage and outcome of disease $[9,10,12,21,31]$. So far all TK studies with clinical material have been performed in serum and are based on the determination of the activity of TK by biochemical techniques.

Recently, we developed a polyclonal antibody, by means of a synthetic peptide corresponding to the Cterminal part of the human thymidine kinase 1 in order to study TK1 as a maker of cell proliferation [15]. The anti-TK1 antibody showed a high specificity both with human and mouse cells as studied by enzymelinked immunosorbent assay, immunoblotting, and immunoprecipition. This antibody for the first time al- 
lows studying the amount of TK1 as a marker of cell proliferation on the cellular level. Here using the antiTK1 antibody, we discuss immunohistochemical findings on the expression and cellular localization of TK1 with emphasis on its relationship with cell cycle. Furthermore, the TK1 expression in cells of various tissues with different proliferating activity was studied in frozen sections from mice. Finally, we studied also the TK1 expression in paraffin embedded human clinical specimens.

\section{Materials and methods}

\subsection{Cells}

Human Hela, PC-3, and CEM wild-type cells as well as resting and phytohemagglutinin + Concanavalin stimulated human lymphocytes were used in this study. Ehrlich ascites tumor (EAT) cells were transplanted into three-month-old female NMRI mice and harvested after 72 hours. All cells were washed in Tris$\mathrm{HCl}$ buffer $(0.1 \mathrm{M}, \mathrm{pH} 7.5)$, and cytocentrifuged onto slides. These were dried at room temperature and fixed with cold acetone at $4{ }^{\circ} \mathrm{C}$ for $10 \mathrm{~min}$, or with $4 \%$ paraformaldehyde at room temperature for $30 \mathrm{~min}$.

\subsection{Tissues}

Mouse stomach, testis, spleen, lung and kidney were removed from a three-month old mouse. Five- $\mu \mathrm{m}$ cryostat tissue sections were cut, air dried, fixed in acetone for $10 \mathrm{~min}$ and stored at $-20^{\circ} \mathrm{C}$ until use.

Specimens from normal human testis and prostate, a malignant teratoma of testis and a poorly differentiated adenocarcinoma of the prostate were fixed in $4 \%$ buffered-formalin and embedded in paraffin. Five $\mu \mathrm{m}$ thick sections were deparaffined in xylene and rehydrated by serial ethanol treatment before immunostaining.

\subsection{Immunostaining}

Immunostaining with the anti-TK1 antibody was performed by means of the avidin-biotin complex $(\mathrm{ABC})$ technique and indirect immunofluorescence.

\subsubsection{Avidin-biotin complex technique}

Cytocentrifuged slides and tissue sections were incubated with the anti-TK1 antibody $(2.5-10 \mu \mathrm{g} / \mathrm{ml}$ in PBS) overnight at $4^{\circ} \mathrm{C}$. After washing, the slides were incubated with a biotinylated secondary antibody (Vector Lab, 1:200 dilution in PBS with normal serum). In order to suppress the activity of endogenous peroxidase in the cells, slides were immersed in $3 \% \mathrm{H}_{2} \mathrm{O}_{2}$ for 8-10 minutes and washed in PBS. Subsequently, avidin-biotin peroxidase complex (Vector Lab, diluted $1: 100)$ was added and the cell material was stained with diaminobenzidine $(1 \mathrm{mg} / \mathrm{ml}$ in PBS with $16 \mu \mathrm{l}$ of $3 \% \mathrm{H}_{2} \mathrm{O}_{2}$ ) at room temperature. In addition, other sections were stained with Texas Red Avidin D (Vector Lab, $1: 50$ in PBS) or FITC Avidin D (Vector Lab; $1: 50$ in PBS) instead of the peroxidase complex staining.

2.3.2. Double labeling immunofluorescence technique Cytocentrifuged slides from PC-3 and Hela cells were fixed in $4 \%$ paraformaldehyde for 30 minutes in room temperature, and immersed in $0.5 \%$ Triton $\times 100$ for 5 minutes. After washing the cells in PBS, the slides were incubated with normal serum, followed by incubation with anti-TK1 antibody (5$10 \mu \mathrm{g} / \mathrm{ml}$ in PBS) overnight at $4^{\circ} \mathrm{C}$. Subsequently, the slides were washed and incubated either with FITCconjugated anti-rabbit secondary antibody (DAKO, Denmark, $1: 20$ diluted in PBS) or with biotinylated antibody conjugated with Texas Red Avidin D. 4,6Diamidino-2-phenylindole dihydrocholoride (DAPI, Sigma, $5 \mu \mathrm{M}$ in PBS) was used for counterstaining the cell nuclei.

In order to determine the relationship between TK1 and the cellular filament system, TK1 was stained with FITC and the cell filament was directly stained with rhodamine phalloidin (Molecular Probes, Eugene, OR, $1: 100$ diluted in PBS) for 5 min.

To identify S-phase cells, human PC-3 cells were labeled with $10 \mu \mathrm{M}$ BrdU (Sigma, St. Louis, MO) in RPMI 1640 medium for $30 \mathrm{~min}$ in $37^{\circ} \mathrm{C}$. Since denaturation of DNA by $\mathrm{HCl}$ influenced the stainability for TK1, before denaturation of the DNA by $2 \mathrm{~N} \mathrm{HCl}$ treatment for 1 hour the PC-3 cells were first stained with Texas Red Avidin D. After washing in PBS the cells were treated with anti BrdU (Boehringer Mannheim, Germany, $6 \mu \mathrm{g} / \mathrm{ml}$ in PBS with $0.1 \%$ BSA), and stained with anti-mouse IgG-FITC (Boehringer Mannheim, Germany, $1: 30$ in PBS) for 30 minutes. 


\subsubsection{Preparation of paraffin embedded sections for immunohistochemistry}

In order to unmask TK1 in formalin fixed, paraffin embedded tissues, deparaffinized and rehydrated tissue sections were immersed into target retrieval solution (DAKO, Denmark) at $95-99^{\circ} \mathrm{C}$ for 30 minutes. A coplin jar with the sections was removed from the water bath and cooled for 20 minutes at room temperature. Before immunostaining the sections were washed three times in PBS for 10 minutes.

\subsubsection{Negative controls for TK1 immunostaining}

As negative control, cells were incubated with PBS instead of the primary antibody in each experiment. To test the specificity of the antibody, the TK1 antibody together with the peptide from the C-terminal of TK1 [15] at 20 times higher concentration than the antibody was used in a competition experiment.

\subsection{Cell separation and cell cycle composition}

To study cells in various stages of the cell cycle, Hela and CEM cells were harvested during exponential growth and separated by elutriation using a Beckman JE-G elutriation rotor with a Beckman J21 B centrifuge [34]. The cell cycle composition was determined by DNA flow cytometry as described previously [3]. The Multicycle program for cell cycle analysis (Phoenix Flow System, San Diego, CA) was used for analysis of the proportion of cells in various cell cycle phases (G1, S and G2/M). The proportion of positive cells was determined in each fraction of the elutriated cells.

\subsection{TK1 expression in relation to cell cycle}

In order to distinguish TK1 negative from TK1 positive cells and to measure various levels of TK1 expression in positive cells, PC-3 cells were cytocentrifuged on slides 72 hours after replenishment of the cultured cells by fresh medium, when the stationary phase of growth was almost reached. The cells treated with the TK1 antibody were stained with Texas Red Avidin D and nuclear DNA was stained with DAPI.

An epi-illumination fluorescence microscope (Orthoplan, Leitz, Germany) equipped with a CF plan APO $60 \times 1.40 \mathrm{NA}$ oil objective (Nikon, Tokyo, Japan) was used. Two filter blocks were applied for the DAPI fluorescence (the excitation light filter was with high transmission between 340 and $380 \mathrm{~nm}$, a beam- splitting mirror with the edge at $400 \mathrm{~nm}$, and a barrier filter with the edge at $430 \mathrm{~nm}$ ) and the Texas Red fluorescence (excitation light filter was with high transmission between 530 and $595 \mathrm{~nm}$, a beam-splitting mirror with the edge at $600 \mathrm{~nm}$, and a barrier filter with the edge at $615 \mathrm{~nm}$ ).

A single chip CCD camera (VI-470, Optronics Engineering, Goleta, CA) with black/white output was used for the measurement. The fluorescence intensities were simultaneously measured with the aid of the Ahrens Cytometry Analysis System (ACAS version 5.00, Bargteheide/Hamburg, Germany) for DNADAPI fluorescence and the VIDAS Image Processing System (version 1.3, Kontron, Germany) for TK1Texas Red fluorescence.

To quantify the intensities of Texas Red and DAPI fluorescence, black and white images were captured using the CCD camera and the specific filter blocks. Since the intensities of DNA-DAPI and TK1 Texas Red were much different, the speed of the video shutter was $1 / 125$ for DAPI and $1 / 15$ for Texas Red, respectively. The segmentation of the cell nuclei stained with DAPI and the cytoplasmic component stained with Texas Red was done by setting the fluorescence thresholds above the image background noise. The cellular DNA content and the expression of TK1 from individual cells were recorded in relative units. When the intensity of the Texas Red fluorescence of the cells was too weak to be separated from the background, these cells were judged as TK1 negative. The Texas Red fluorescence intensity of TK1 positive cells was quantified and the DAPI fluorescence intensity of all cells were related to the corresponding TK1 negative and positive cells.

\section{Results}

\subsection{Intracellular localization of TK1}

TK1 was exclusively located in the cytoplasm of the cells. This was observed both in smears from various cell lines and stimulated human lymphocytes, in histological sections of the normal mouse and sections from normal and malignant human specimens. Typically, the positive labeling is built up by spots of granules and concentrated mostly near the nuclei (Fig. 1A). TK1 was obviously not associated with cell filament (Fig. 1B and C). 

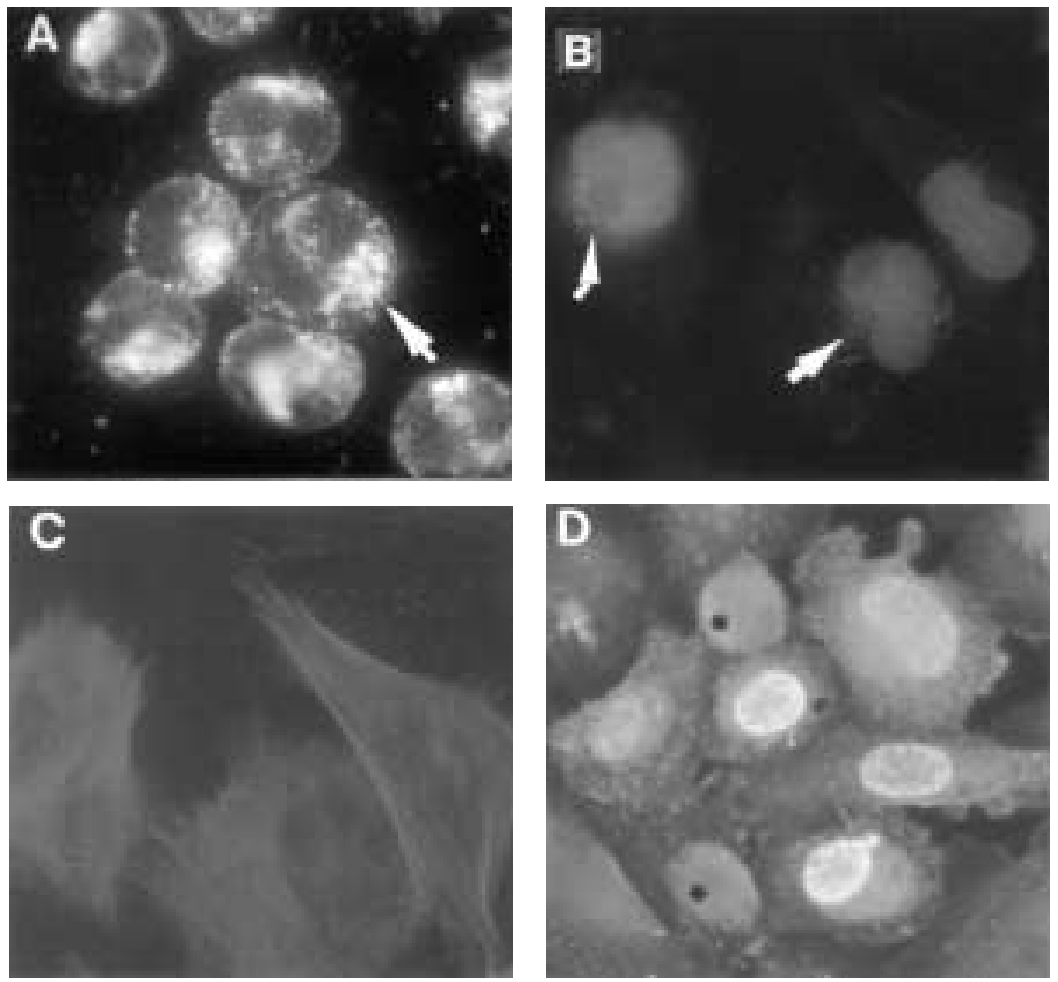

Fig. 1. A, Immunofluorescence staining of CEM cells with the anti TK1 antibody (arrows); B, Triple fluorescence stained Hela cells: TK1 (FITC, green, arrows), cellular filament (Rhodamine, red) and DNA (DAPI, blue); C, Cytoskeleton (Rhodamine, red) in same cells as in Fig. 1B; D, Double immunofluorescence stained PC-3 cells: TK1 (Rhodamine, red), anti BrdU (FITC, green), TK1 positive cells and BrdU negative ( * ) presuming late G1 cells.

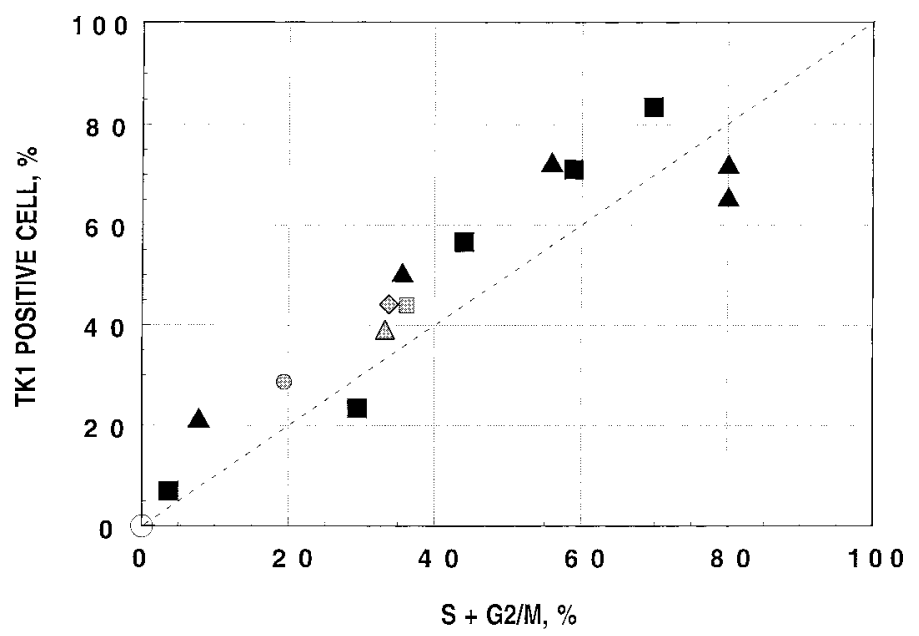

Fig. 2. The relationship between the percent of S+G2/M cells as measured by DNA flow cytometry and the cytologically TK1 positive cells. ( $\mathbf{\Delta})$

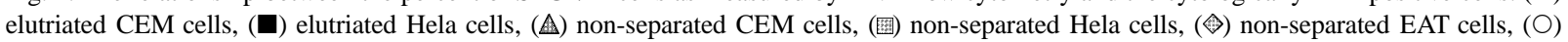

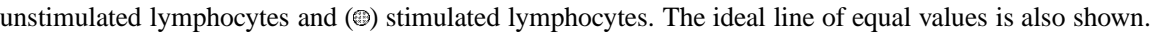

\subsection{Expression of TK1 in relation to the cell cycle}

In PC-3 cells pulse-labeled with BrdU, the expression of TK1 and BrdU was simultaneously studied.
When counting 600 cells, 19\% were BrdU positive while $21 \%$ were TK1 positive. Thus TK1 positive cell were not only found in cells positive for BrdU but also 




Fig. 3. The DNA content of 520 randomly measured cells (gray) of which 152 were TK1 positive (black). Fluorescence image cytometry of double stained PC-3 cells (TK1-Texas Red, DNA-DAPI).

in about $2 \%$ of BrdU negative cells. Figure 1D shows an example of some BrdU negative cells with positive TK1 staining.

Cultured CEM and Hela cells were used in order to study the cell cycle related expression of TK1. Exponentially growing cells were separated by elutriation centrifugation as described in Material and methods. In addition, non-separated CEM, Hela and EAT cells as well as unstimulated and stimulated lymphocytes were studied. In Fig. 2 the percent of cells in S-phase and G2 of the cell cycle as determined by DNA flow cytometry and the percent of TK1 positive cells as determined microscopically are shown. Most of the cell types studied had slightly but systematically higher fractions of TK1 positive cell as compared to the fractions of $\mathrm{S}+\mathrm{G} 2+$ $\mathrm{M}$ cells. The exceptions were the two elutriation fractions which contained a larger number of G2/M cells.

In a further study of PC-3 cells, more than 500 individual cells were measured by fluorescence image cytometry with respect to their DNA content and the existence of TK1 positive and negative cells (Fig. 3). A high fraction of TK1 positive cell at the border of G1/S-phase was observed.

\subsection{Amount of TK1 in relation to cell cycle}

In the experiments described above, we studied the existence of TK1 positive cells in relation to cells in different cycle phases but not the amount of TK1 in these cells. The latter question was studied by quantitative measurements of TK1 in individual cell simultane-

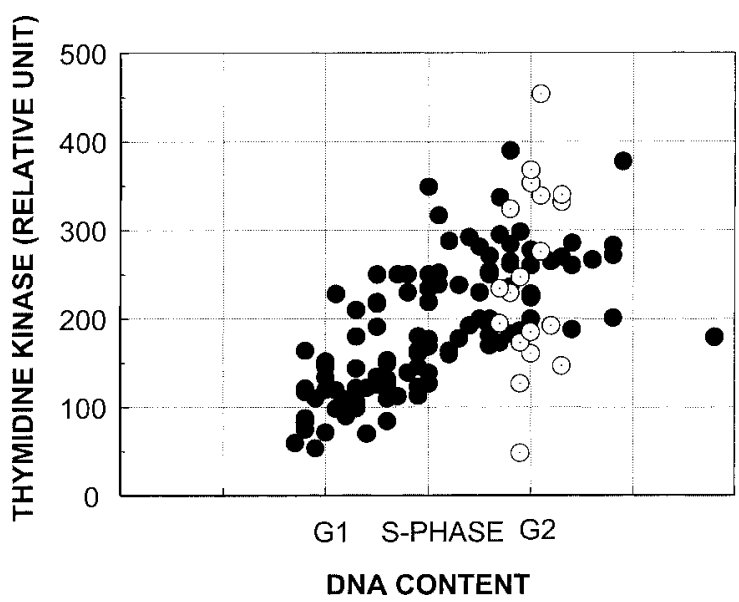

Fig. 4. The relationship between fluorescence intensity of TK1 positive cells (Texas Red) and DNA content (DAPI) in 152 PC-3 cells. Mitotic cells are indicated by open circles.

ously characterized by their DNA content. In Fig. 4, a three to four fold increase in the amount of TK1 during passage of cells from G1 through S-phase to G2 can be seen. Mitotic cells may have high amounts of TK1, but also low amounts of TK1 can be observed.

\subsection{TK1 expression in tissue sections of normal mouse}

In normal tissues from the mouse, TK1 was exclusively found in the regions of tissues known to contain proliferating cells (Table 1). For example, the secondary spermatocyte layer of testis (Fig. 5A), the chief 
Table 1

Cell types reacting with the anti TK1 antibody from mouse and human tissues

\begin{tabular}{|c|c|c|}
\hline Organ & Cell type & Immunostaining \\
\hline \multicolumn{3}{|l|}{ Mouse tissues } \\
\hline \multirow[t]{2}{*}{ Spleen } & Germinal centre cells & + \\
\hline & Red pulp cells & - \\
\hline \multirow[t]{2}{*}{ Testis } & Undiferentiated spermatogonia & + \\
\hline & Sperm cells & - \\
\hline \multirow[t]{2}{*}{ Stomach } & Gastric surface epithelium & - \\
\hline & Epithelium in the fundus & $+/-$ \\
\hline \multirow[t]{2}{*}{ Kidney } & Tubular cells & - \\
\hline & Glomerular cells & - \\
\hline Liver & Hepatocytes & - \\
\hline Lung & Epithelium & - \\
\hline \multicolumn{3}{|c|}{ Human non-malignant tissues } \\
\hline \multirow[t]{2}{*}{ Testis } & Undiferentiated spermatogonia & + \\
\hline & Sperm cells & - \\
\hline Prostate & Hyperplasia & - to $-/+$ \\
\hline Peripheral & Lymphocytes & - \\
\hline \multirow[t]{2}{*}{ blood } & Monocytes & - \\
\hline & Stimulated lymphocytes & + \\
\hline \multicolumn{3}{|l|}{ Human malignancies } \\
\hline \multicolumn{3}{|l|}{ Malignant teratoma } \\
\hline \multirow[t]{3}{*}{ from human testis } & Endodermic comparment & + \\
\hline & Mesodermic comparment & + \\
\hline & Ectodermic compartment & + \\
\hline \multicolumn{3}{|l|}{ Adenocarcinoma } \\
\hline \multirow[t]{6}{*}{ of prostate } & Tumor cells & $-/+$ to +++ \\
\hline & Endothelial cells & \\
\hline & of blood vessel in the tumor & $-/+$ \\
\hline & Normal cells in the prostatic glands & - \\
\hline & Endothelial cells of blood vessel & \\
\hline & in the normal part & - \\
\hline
\end{tabular}

cells in the basal portion of the gastric glands, or the germinal center in the spleen (Fig. 5B) all contain TK1 positive cells. Tissues usually lacking cell proliferation such as cells of the red pulp of the spleen (Fig. 5C) or the lung (Fig. 5D) and kidney were also lacking TK1 positive cells.

\subsection{TK1 expression in clinical material}

Paraffin embedded human tissue sections from testis and prostate show examples of clinical applications of the TK1 antibody. The basal layer of the spermatogonia, representing the proliferation zone of the normal testis showed strong TK1 staining (Fig. 6A). Only background fluorescence was found in mature germ cells and sperms. A high-grade prostate carcinoma shown in Fig. 6B expressed strong TK1 staining, while stromal cells were always negative. As a further example positive reaction was demonstrated in the embryonic bone component of a malignant teratoma of the human testis (Fig. 6C). Various tissues studied with the anti TK1 antibody are listed in Table 1.

\section{Discussion}

In mammalian cells, the activity of TK1 is tightly controlled during the cell cycle. Enzyme activity is low or absent during $\mathrm{G} 1$, but increases dramatically at the boarder of G1/S-phase. It is known from bio- 



Fig. 5. Immunoperoxidase stained frozen section of mouse tissues. A, testis: the secondary spermatocytes are TK1 positive (brown, counterstained with hematoxylin); B, germinal center of the spleen; C, red pulp of the spleen; D, lung.

chemical studies that the cell cycle related increase in TK1 activity is combined with increased expression of mRNA as well as of the TK1 protein [2, $14,19,25,32,35,38]$. Several molecular mechanisms involved in the up-regulation of the TK1 at the G1/Sphase border have been described [7]. The transcription factor E2F which interacts with cyclins and kinase binds to the TK1 gene promoter resulting in the up-regulation of the mRNA production. Overexpression of the E2F gene products induces quiescent cells to enter S-phase combined with overexpression of TK1 [27]. Hypermethylation of the TK1 gene promoter decreases the mRNA transcription and TK1 expression [1].

In our previous work, an anti TK1 antibody was produced against the C-terminal peptide of human TK1 [15]. It specifically reacted with both human and mouse TK1 and has been characterized by ELISA, immunoblotting, immunoprecipitation and immunostaining of cultured cells [15]. Here, we demonstrate that TK1 is exclusively localized in the cytoplasm of both cultured cells and cells in tissue sections. In studies with fluorescent protein fused with human or viral TK1, cytoplasmic fluorescence but also low level of fluorescence in the cell nuclei was found [18]. The intracellular localizations of various viral TKs and as well the other deoxnucleoside kinases were recently reinvestigated and nuclear forms of these enzymes were reported $[6,13,18]$. The localization of human TK1 thus, differs from the viral TK:s and from the expression of $\mathrm{Ki}-67$, proliferating cell nuclear antigen and anti BrdU which all are localized in the cell nuclei. The heterogeneous and granular patterns of TK1 staining indicate specific ultrastructure binding within the cytoplasm. However, TK1 seems not to be associated with cell filaments and the reason for the granular appearance of TK1 remains to be determined.

Our cell cycle related studies show that TK1 is not only specific for proliferating S-phase and G2 cells, but also for late G1 cells (Fig. 3). Some TK1 negative cells in S-phase may indicate the existence of resting S-phase cells when reaching the plateau phase of cell growth. Also, TK1 positive cells could be found in the absence of BrdU labeled cells (Fig. 1D). Here we demonstrated a linear increase in TK1 during the passage of cells from G1 to G2 of the cell cycle (Fig. 4). Some mitotic cells had the same level of TK1 as G2- 

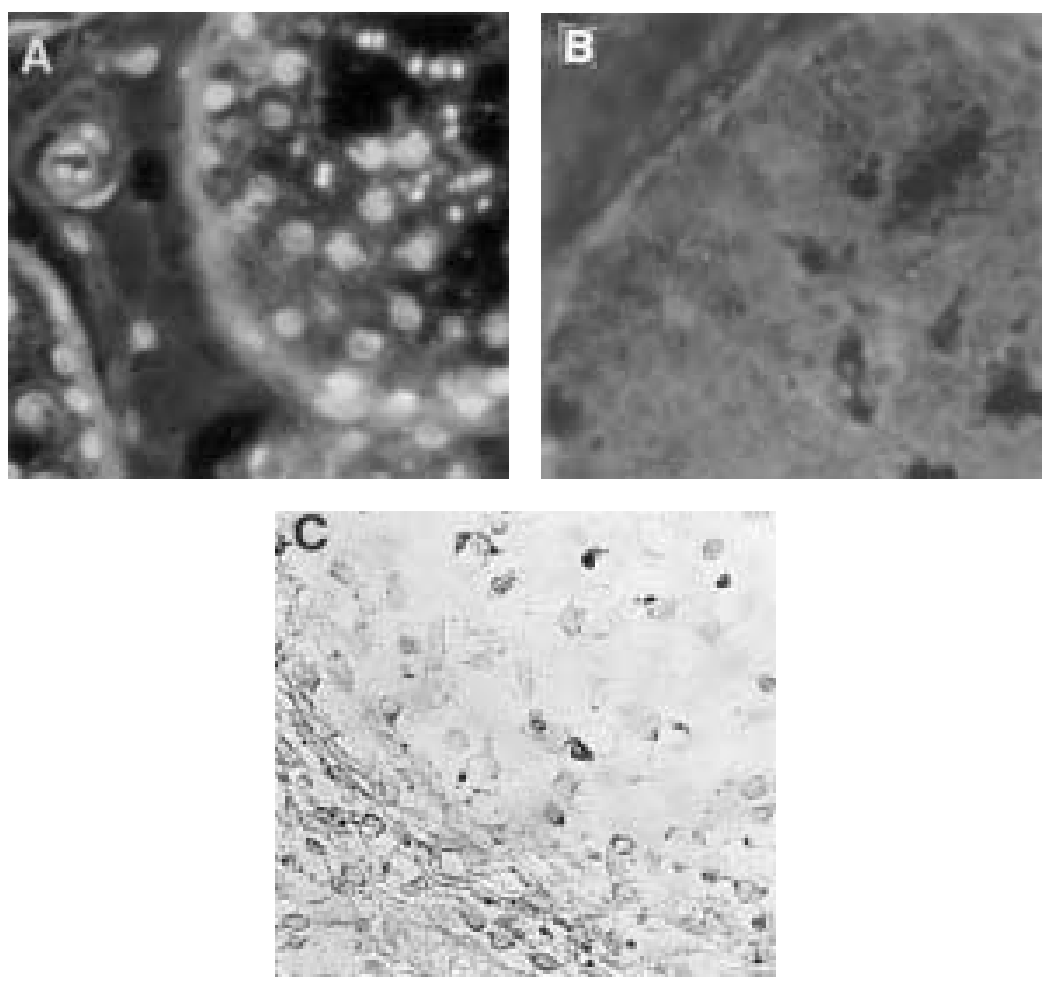

Fig. 6. A, Immunofluorescence of the anti-TK1 antibody in a paraffin embedded section from a normal human testis: the secondary spermatocytes are TK1 positive (Texas Red, red), cellular DNA (DAPI, blue); B, Immunofluorescence of the anti-TK1 antibody in a paraffin embedded section from a human poorly differentiated prostate carcinoma: tumor cell are TK1 positive (FITC, green), stroma cells are TK1 negative, cellular DNA (DAPI, blue); C, Immunoperoxidase stained mesodermic components from a malignant teratoma of a human testis.

cells while others had much lower levels, which indicates a rapid degradation of the TK1 protein during mitosis, as was also described by Sherley and Kelly [32]. A similar rapid degradation during $M$ phase has been observed in case of the ribonucleotide reductase R2 subunit (L. Thelander, personal communication), and this type of cell cycle dependent proteolyses may be a common mechanism for the control of DNA precursor enzymes.

The occurrence of TK1 positive cells in sections from various tissues is in agreement with the known rate of cell proliferation in these tissues. Of particular clinical interest is that the antibody can be used not only with acetone and paraformaldehyde fixed cells but also in paraffin embedded archival specimens. This was observed both with benign and malignant specimens from prostate and testis. Thus, the present observations strongly suggest that the anti-TK1 antibody is useful not only for investigations of cell cycle regulation and cell proliferation in experimental cell systems but also as a marker of cell proliferation in clinical histopathology. A study in premalignant and ma- lignant lesions of the prostate was been submitted for publication.

\section{Acknowledgement}

This work was supported by the King Gustaf V Jubilee Foundation and the Cancer Society of Stockholm.

\section{References}

[1] V. Avramis, R. Kwock, M. Solorzano and E. Gomperts, Evidence of in vitro development of drug resistance to azidothymidine in T-lymphocytic leukemia cell lines (Jurkat E6-1/AZT100 ) and in pediatric patients with HIV-1 infection, J. Acquir. Immune Defic. Syndr. 6 (1993), 1287-1296.

[2] T.P. Brent, Periodicity of DNA synthetic enzymes during the HeLa cell cycle, Cell Tiss. Kinet. 4 (1971), 297-305.

[3] J. Castro, T. Heiden, N. Wang and B. Tribukait, Preparation of cell nuclei from fresh tissues for high-quality DNA flow cytometry, Cytometry 14 (1993), 793-804.

[4] A.M. Davidoff, P.A. Humphrey, J.D. Iglehart and J.R. Marks, Genetic basis for p53 overexpression in human breast cancer, Proc. Natl. Acad. Sci. USA 88 (1991), 5006-5010. 
[5] P.N. Dean, F. Dolbeare, H. Gratzner, G.C. Rice and J.W. Gray, Cell-cycle analysis using a monoclonal antibody to BrdUrd, Cell Tiss. Kinet. 17 (1984), 427-436.

[6] B. Degreve, M. Johansson, E. De Clercq, A. Karlsson and J. Balzarini, Differential intracellular compartmentalization of herpetic thymidine kinases (TKs) in TK gene-transfected tumor cells: molecular characterization of the nuclear localization signal of herpes simplex virus type 1 TK, J. Virol. 72 (1998), 9535-9543.

[7] Q. Dou and A. Pardee, Transcriptional activation of thymidine kinase, a marker for cell cycle control, Prog. Nucleic Acid Res. Mol. Biol. 53 (1996), 197-217.

[8] J. Gerdes, U. Schwab, H. Lemke and H. Stein, Production of a mouse monoclonal antibody reactive with a human nuclear antigen associated with cell proliferation, Int. J. Cancer $\mathbf{3 1}$ (1983), 13-20.

[9] J.S. Gronowitz, R. Bergstrom, E. Nou, S. Pahlman, O. Brodin, S. Nilsson and C.F. Kallander, Clinical and serologic markers of stage and prognosis in small cell lung cancer. A multivariate analysis, Cancer 66 (1990), 722-732.

[10] J.S. Gronowitz, H. Hagberg, C.F. Kallander and B. Simonsson, The use of serum deoxythymidine kinase as a prognostic marker, and in the monitoring of patients with non-Hodgkin's lymphoma, Br. J. Cancer 47 (1983), 487-495.

[11] P.A. Hall and D.A. Levison, Review: assessment of cell proliferation in histological material, J. Clin. Pathol. 43 (1990), 184-192.

[12] M. Hallek, L. Wanders, S. Strohmeyer and B. Emmerich, Thymidine kinase: a tumor marker with prognostic value for non-Hodgkin's lymphoma and a broad range of potential clinical applications, Ann. Hematol. 65 (1992), 1-5.

[13] P. Hatzis, A.S. Al-Madhoon, M. Jullig, T.G. Petrakis, S. Eriksson and I. Talianidis, The intracellular localization of deoxycytidine kinase, J. Biol. Chem. 273 (1998), 30 239-30 243.

[14] Q. He, S. Skog and B. Tribukait, Cell cycle related studies on thymidine kinase and its isoenzymes in Ehrlich ascites tumours, Cell Prolif. 24 (1991), 3-14.

[15] Q. He, S. Skog, N. Wang, S. Eriksson and B. Tribukait, Characterization of a peptide antibody against a C-terminal part of human and mouse cytosolic thymidine kinase, which is a marker for cell proliferation, Eur. J. Cell. Biol. 70 (1996), 117-124.

[16] M. Hollstein, D. Sidransky, B. Vogelstein and C.C. Harris, p53 mutations in human cancers, Science 253 (1991), 49-53.

[17] S. Jain, M.I. Filipe, P.A. Hall, N. Waseem, D.P. Lane and D.A. Levison, Prognostic value of proliferating cell nuclear antigen in gastric carcinoma, J. Clin. Pathol. 44 (1991), 655-659.

[18] M. Johansson, S. Brismar and A. Karlsson, Human deoxycytidine kinase is located in the cell nucleus, Proc. Natl. Acad. Sci. USA 94 (1997), 11 941-11 945.

[19] M.G. Kauffman and T.J. Kelly, Cell cycle regulation of thymidine kinase: residues near the carboxyl terminus are essential for the specific degradation of the enzyme at mitosis, Mol. Cell. Biol. 11 (1991), 2538-2546.

[20] G. Landberg and G. Roos, The cell cycle in breast cancer, APMIS 105 (1997), 575-589.

[21] A. Lewenhaupt, P. Ekman, P. Eneroth and B. Nilsson, Tumour markers as prognostic aids in prostatic carcinoma, $\mathrm{Br}$. J. Urol. 66 (1990), 182-187.
[22] R.D. Mashal, S. Lester, C. Corless, J.P. Richie, R. Chandra, K.J. Propert and A. Dutta, Expression of cell cycle-regulated proteins in prostate cancer, Cancer Res. 56 (1996), 4159-4163.

[23] S. Masood, Prediction of recurrence for advanced breast cancer. Traditional and contemporary pathologic and molecular markers, Surg. Oncol. Clin. North Am. 4 (1995), 601-632.

[24] T.W. McGarvey and S.B. Malkowicz, The role of the cell cycle in genitourinary carcinoma, World J. Urol. 14 (1996), 310-317.

[25] W. Mikulits, M. Hengstschlager, T. Sauer, E. Wintersberger and E.W. Mullner, Overexpression of thymidine kinase mRNA eliminates cell cycle regulation of thymidine kinase enzyme activity, J. Biol. Chem. 271 (1996), 853-860.

[26] B. Nordstrom, P. Strang, R. Bergstrom, S. Nilsson and B. Tribukait, A comparison of proliferation markers and their prognostic value for women with endometrial carcinoma. Ki67 , proliferating cell nuclear antigen, and flow cytometric Sphase fraction, Cancer 78 (1996), 1942-1951.

[27] E. Ogris, H. Rotheneder, I. Mudrak, A. Pichler and E. Wintersberger, A binding site for transcription factor E2F is a target for trans activation of murine thymidine kinase by polyomavirus large $\mathrm{T}$ antigen and plays an important role in growth regulation of the gene, J. Virol. 67 (1993), 1765-1771.

[28] M.G. Patti and D. Owen, Prognostic factors in esophageal cancer, Surg. Oncol. Clin. North Am. 6 (1997), 515-531.

[29] C.M. Quinn and N.A. Wright, The clinical assessment of proliferation and growth in human tumours: evaluation of methods and applications as prognostic variables [see comments], J. Pathol. 160 (1990), 93-102.

[30] N.R. Rodrigues, A. Rowan, M.E. Smith, I.B. Kerr, W.F. Bodmer, J.V. Gannon and D.P. Lane, p53 mutations in colorectal cancer, Proc. Natl. Acad. Sci. USA 87 (1990), 7555-7559.

[31] S. Romain, I.J. Christensen, O. Chinot, I. Balslev, C. Rose, P.M. Martin and S.M. Thorpe, Prognostic value of cytosolic thymidine kinase activity as a marker of proliferation in breast cancer, Int. J. Cancer 61 (1995), 7-12.

[32] J.L. Sherley and T.J. Kelly, Regulation of human thymidine kinase during the cell cycle, J. Biol. Chem. 263 (1988), 83508358.

[33] R. Silvestrini, M.G. Daidone, A. Luisi, M. Mastore, M. Leutner and B. Salvadori, Cell proliferation in 3,800 node-negative breast cancers: consistency over time of biological and clinical information provided by $3 \mathrm{H}$-thymidine labelling index, Int. J. Cancer 74 (1997), 122-127.

[34] S. Skog, B. Tribukait and G. Sundius, Energy metabolism and ATP turnover time during the cell cycle of Ehrlich ascites tumour cells, Exp. Cell Res. 141 (1982), 23-29.

[35] P. Stuart, M. Ito, C. Stewart and S.E. Conrad, Induction of cellular thymidine kinase occurs at the mRNA level, Mol. Cell. Biol. 5 (1985), 1490-1497.

[36] B. Tribukait, Clinical DNA flow cytometry, Med. Oncol. Tumor Pharmacother. 1 (1984), 211-218.

[37] P.J. van Diest, R.J. Michalides, L. Jannink, P. van der Valk, H.L. Peterse, J.S. de Jong, C.J. Meijer and J.P. Baak, Cyclin D1 expression in invasive breast cancer. Correlations and prognostic value, Am. J. Pathol. 150 (1997), 705-711.

[38] H.C. Yang and A.B. Pardee, Insulin-like growth factor I regulation of transcription and replicating enzyme induction necessary for DNA synthesis, J. Cell. Physiol. 127 (1986), 410-416. 




The Scientific World Journal
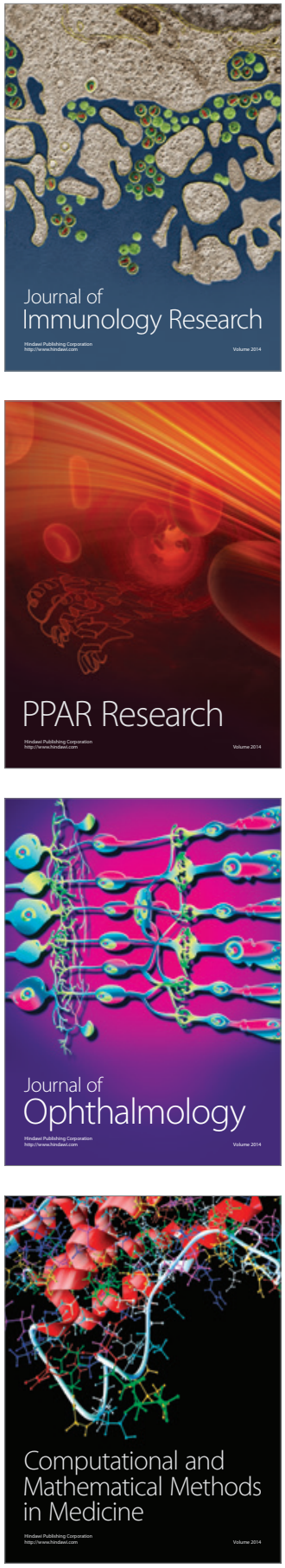

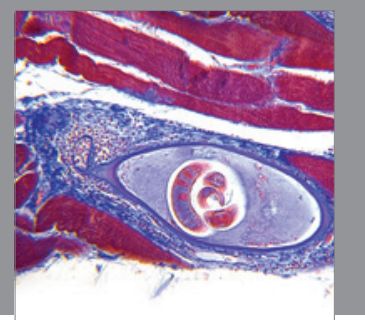

Gastroenterology

Research and Practice
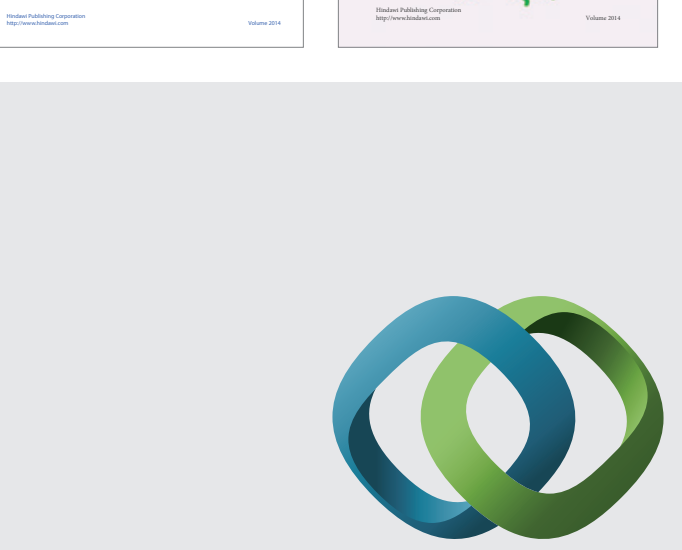

\section{Hindawi}

Submit your manuscripts at

http://www.hindawi.com
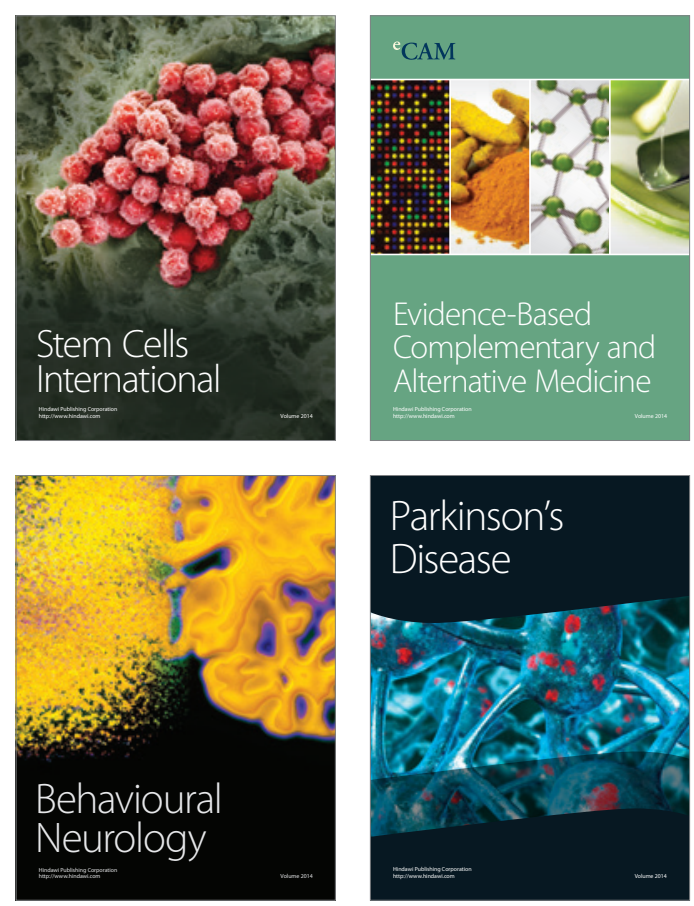

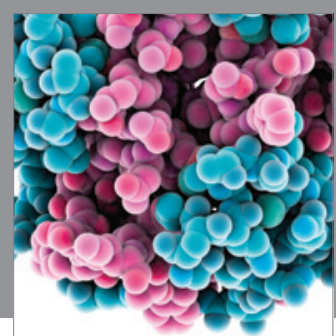

Journal of
Diabetes Research

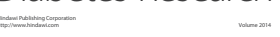

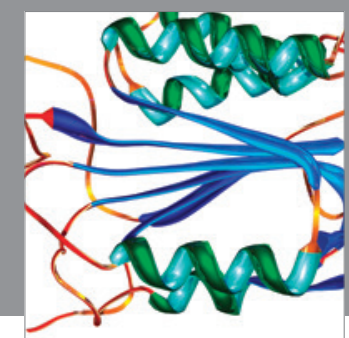

Disease Markers
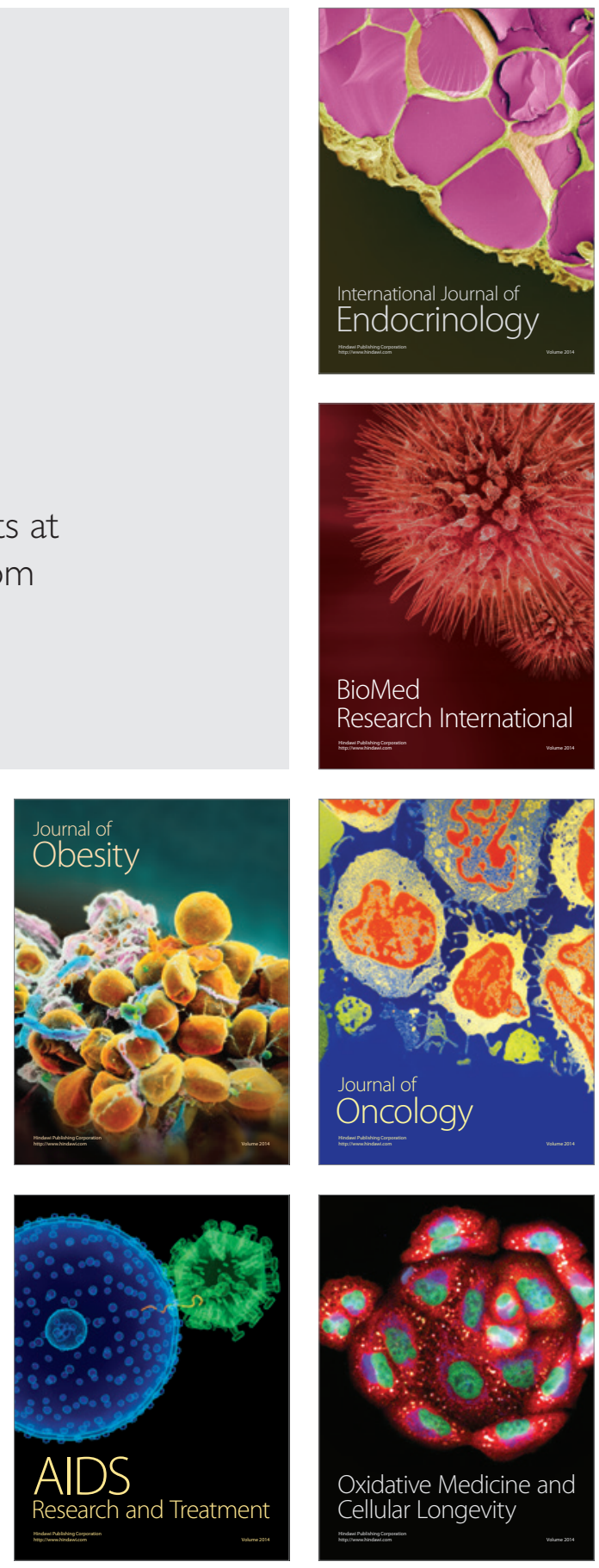